\title{
Comparison of the total phenolic content, total anthocyanin content and antioxidant activity of polyphenol-rich fruits grown in Chile
}

\author{
Carolina Fredes ${ }^{1}$, Gloria Montenegro ${ }^{1}$, Juan Pablo Zoffoli ${ }^{2}$, Francisca \\ Santander ${ }^{1}$, and Paz Robert ${ }^{3}$ \\ ${ }^{1}$ Departamento de Ciencias Vegetales and ${ }^{2}$ Departamento de Fruticultura, Facultad de Agronomía e \\ Ingeniería Forestal, Pontificia Universidad Católica de Chile. Avenida Vicuña Mackenna 4860, Macul, \\ Santiago, Chile. \\ ${ }^{3}$ Departamento de Ciencia de los Alimentos y Tecnología Química, Facultad de Ciencias Químicas y \\ Farmacéuticas, Universidad de Chile. Sergio Livingstone Pohlhammer 1007, Independencia, Santiago, Chile.
}

\begin{abstract}
C. Fredes, G. Montenegro, J.P. Zoffoli, F. Santander, and P. Robert. 2014. Comparison of the total phenolic content, total anthocyanin content and antioxidant activity of polyphenol-rich fruits grown in Chile. Cien. Inv. Agr. 41(1): 49-60. In the last 10 years, interest in research on polyphenol-rich fruit species has increased due to the potential health benefits of these species, mainly attributed to their high anthocyanin content and antioxidant activity. Six polyphenol-rich fruit species (blueberries, raspberries, blackberries, strawberries, pomegranates and maqui berries) were harvested at the same maturity stage during the same growing season and were compared according to their total phenolic (Folin-Ciocalteu method) and total anthocyanin ( $\mathrm{pH}$ differential method) contents and antioxidant activity using ferricreducing antioxidant power (FRAP assay) and 2,2-diphenylpicrylhydrazyl (DPPH) radical scavenging capacity methods. With the results of this study, the polyphenolic status of the main polyphenol-rich fruit species that are grown in Chile were compared, and maqui berry showed the highest total phenolic (14.6 g gallic acid equivalent $\mathrm{kg}^{-1}$ of fresh weight [ $\left.\mathrm{g} \mathrm{GAE} \mathrm{kg}^{-1} \mathrm{FW}\right]$ ), total anthocyanin (9.3 g cyanidin-3-glu kg-1 of fresh weight [g cy-3-glu kg-1 FW]) contents, and antioxidant activity $\left(152.0 \mathrm{mmol} \mathrm{Fe} \mathrm{kg}^{2+}\right.$ of fresh weight $\left[\mathrm{mmol} \mathrm{Fe} \mathrm{kg}^{2+} \mathrm{kg}^{-1} \mathrm{FW}\right.$ ] and $1.5 \mathrm{mg}$ of fresh weight $[\mathrm{FW}]$ ) with significant differences from the other fruit species that were analyzed. Nevertheless, bioavailability studies to test the benefits of the species' dietary antioxidants should be performed in order to establish scientific evidence in this area.
\end{abstract}

Key words: Berries, DPPH, FRAP, maqui, pomegranate.

\section{Introduction}

Berry fruits have long been regarded as having considerable health benefits due to their nutritional attributes, particularly their total antioxidant activ- ity against cellular oxidation reactions (Seeram, 2008). These benefits have stimulated research to regularly investigate the phenolic status and antioxidant activity of distinct berry fruit species and new varieties in different countries.
Received July 12, 2013. Accepted March 20, 2014. Corresponding author: cpfredes@uc.cl
A great variety of species exist from diverse botanical families (blueberries [Vaccinium cor- 
ymbosum L., Ericaceae], strawberries [Fragaria ananassa Duch., Rosaceae], red raspberries [Rubus idaeus L., Rosaceae], and blackberries [Rubus sp., Rosaceae]), whose small purple or red fruits are denoted as berries. In botanical terms, a berry is a fruit with many seeds and mesocarp flesh that evolves from a flower with a superior ovary. Therefore, in strictly botanical terms, none of the above mentioned fruits are true berries. Due to the various botanical families and botanical fruits to which polyphenol-rich fruit species belong, a wide range of phenolic contents and corresponding antioxidant activities may be expected according to the specific compounds that are present in these species.

The anthocyanins are responsible for the color of polyphenol-rich fruit species (Capocasa et al., 2008a; Koca and Karadeniz, 2009; Caliskan and Bayazit, 2012; Josuttis et al., 2012; Skrede et al., 2012; Wang et al., 2012a). In addition to their colorant properties, anthocyanins have been associated with a wide range of biological, pharmacological, anti-inflammatory, antioxidative, and chemoprotective properties (de PascualTeresa and Sanchez-Ballesta, 2008).

Chile is becoming an important grower of cultivated polyphenol-rich fruits (blueberries, strawberries, red raspberries and blackberries), and the Chilean blueberry industry has risen globally to be the world's largest exporter (ODEPA, 2012). Pomegranate (Punica granatum Linn., Punicaceae) is an emergent Chilean crop with approximately 500 ha planted, and, internationally, pomegranate fruit has been recognized for its high polyphenol content and antioxidant activity (Zhao et al., 2013).

In recent years, wild fruits from South America have gained increased interest mainly due to the potential health benefits of novel exotic fruit (Schreckinger et al., 2010). Among the native berries from Chile, the maqui fruit (Aristotelia chilensis [Mol.] Stuntz, Elaeocarpaceae) has acquired special interest due its high polyphenol content and antioxidant activity (Miranda-Rottmann et al., 2002; Araya et al., 2006). The high variability of analytical method that is used to quantify the phenolic content and that is associated with sample extraction has been reported; therefore, a valid comparison among species and varieties is not always performed correctly (Jimenez et al., 2011). To perform a valid comparison of the phenolic levels in fruits and their derived products, it is necessary to use the same method of extraction and a comparative methodology for polyphenols and antioxidant activity quantification. The objective of this study was to compare the total phenolic and anthocyanin contents and antioxidant activity (FRAP and radical DPPH methods) of polyphenol-rich fruit species that are grown in Chile using the same extraction and analytical methods.

\section{Materials and methods}

\section{Fruit samples}

The cultivated fruit species were obtained from the main commercial production area of Chile (from the Valparaíso Region to the Bio Bio Region), in which the crops were grown under integrated pest management practices. Blueberry varieties (Aurora, Brigitta, Elliot, Legacy, Liberty and Ozarkblue), red raspberry (var. Heritage), blackberry varieties (Navaho, Prime-Jim and Prime-Jan), strawberry varieties (Camarosa, Sabrina, Sabrosa and Siba) and pomegranate (var. Wonderful) were analyzed. Different ecotypes of wild maqui berries were collected from four different geographical areas (from the Valparaíso Region to the Araucanía Region). Each of the four sampling sites featured similar soil conditions, and no external irrigation or fertilization was used in any of these wild crafted sites.

The fruit samples (100 fruits) were taken randomly from the upper, middle and lower canopy and were transferred on the same day in a cooler $\left(6^{\circ} \mathrm{C}\right)$ to the laboratory for analysis. Then, each sample 
was separated into two groups for the analytical procedures. All of the parameters were analyzed in triplicate.

The fruit maturity was determined for each variety. The berry weight was determined from the mean weight of 30 fresh fruits. Slurries were used to determine total soluble solid (SS) content by refractometry (ATAGO-Spectrum Technologies, Plainfield, Illinois, USA). According to these results, the fruits with similar SS values within each species/variety were analyzed. Table 1 shows the species/varieties, the date of harvest, the geographical origin, the SS content and the fruit weight of the fruit samples that were analyzed.

\section{Determination of the total phenolic (TP) content}

The samples for the antioxidant analysis were prepared using acidified methanol $(0.1 \% \mathrm{HCL})$. A ground sample $(1.5 \mathrm{~g})$ of whole fruit or fruit arils (in the case of pomegranate) was vigorously mixed with $6 \mathrm{~mL}$ of acidified methanol $(0.1 \%$ $\mathrm{HCl})$ for $1 \mathrm{~h}$ and centrifuged for $15 \mathrm{~min}$ at 3000 $\mathrm{rpm}$. The supernatant was collected in a $25 \mathrm{~mL}$ volumetric flask. The residue was treated twice more with $6 \mathrm{~mL}$ acidified methanol followed by 15 min of centrifugation. The supernatants were collected and standardized to a final volume of $25 \mathrm{~mL}$. The TP contents were determined by the Folin-Ciocalteu method (Singleton and Rossi, 1965). Fruit extract, distilled water, and Folin-Ciocalteu's phenol reagent were added, and the mixture was incubated for $3 \mathrm{~min}$, after which $20 \%$ sodium carbonate was added. After $30 \mathrm{~min}$, the absorbance was measured in a spectrophotometer (Unicam UV/VIS ATI Unicam, Cambridge, UK) at $765 \mathrm{~nm}$. Gallic acid was used as the standard according to a calibration curve $\left(133.8-428 \mu \mathrm{g} \mathrm{mL}^{-1} ; \mathrm{R}^{2}=\right.$ 0.9901). The results were expressed as grams of gallic acid equivalent per kilogram of fresh weight ( $\mathrm{g} \mathrm{GAE} \mathrm{kg}^{-1} \mathrm{FW}$ ).

\section{Determination of the total anthocyanin (TA)} content

The total anthocyanin contents were determined by the $\mathrm{pH}$ differential method (Lee et al., 2005) using a spectrophotometer (Unicam UV/VIS ATI UNICAM, Cambridge, UK). The absorbance of the fruit extract was measured at 515 and 700 $\mathrm{nm}$ in $\mathrm{pH} 1.0$ and 4.5 buffers, respectively, using $\mathrm{A}=(\mathrm{A} 515$ - A700) $\mathrm{pH} 1.0$ - (A515 - A700) $\mathrm{pH} 4.5$ with a molar extinction coefficient of 26,900 . The results were expressed as grams of cyanidin-3-glucoside equivalent per kilogram of fresh weight (g cy-3-glu kg-1 FW).

\section{Determination of the antioxidant activity (AA)}

The antioxidant activity was determined by the ferric-reducing antioxidant power (FRAP) method as previously described (Benzie and Strain, 1996) and by the free radical, 2.2- diphenylpicrylhydrazyl $\left(\mathrm{DPPH}^{\circ}\right)$ method as previously described (Brand-Williams et al., 1995) using a spectrophotometer (Unicam UV/VIS ATI UNICAM, Cambridge, UK). The FRAP method was performed using three aqueous stock solutions containing $0.1 \mathrm{~mol} \mathrm{~L}^{-1}$ acetate buffer ( $\mathrm{pH} 3.6$ ), $10 \mathrm{mmol} \mathrm{L}^{-1}$ TPTZ [2,4,6-tris(2-pyridyl)-1,3,5triazine] that was acidified with concentrated $\mathrm{HCl}(40 \mathrm{mM})$, and $20 \mathrm{mmol} \mathrm{L}^{-1} \mathrm{FeCl}_{3}$. The stock solutions were combined $(10: 1: 1 \mathrm{v} / \mathrm{v} / \mathrm{v})$ to obtain the FRAP reagent immediately prior to the analysis; $2.7 \mathrm{~mL}$ FRAP reagent, $270 \mu \mathrm{L} \mathrm{mEq}$ $\mathrm{H}_{2} \mathrm{O}$ and $30 \mu \mathrm{L}$ sample extract were mixed. After $10 \mathrm{~min}$, the absorbance was measured at $593 \mathrm{~nm}$. The aqueous standard solutions of $\mathrm{FeSO}_{4} 7 \mathrm{H}_{2} \mathrm{O}$ $(0-1000 \mu \mathrm{M})$ were used for the calibration curve, and the results were expressed as millimoles $\mathrm{Fe}^{2+}$ per kilogram of fresh weight $\left(\mathrm{mmol} \mathrm{Fe}{ }^{2+} \mathrm{kg}^{-1}\right.$ FW). The DPPH method was conducted using the DPPH reagent that was diluted in methanol (2\%). For the analysis, $0.1 \mathrm{~mL}$ sample was mixed with $3.9 \mathrm{~mL}$ DPPH methanolic solution. After $30 \mathrm{~min}$, the absorbance was measured 
at $517 \mathrm{~nm}$. The results were expressed as $\mathrm{EC}_{50}$ (milligrams of sample that bleached $50 \%$ of the DPPH methanolic solution) by the construction of a kinetic curve for each sample.

\section{Statistical analysis}

The results were expressed as the mean, standard error of the mean (SEM) and coefficient of variation (the ratio of the standard deviation to the mean, $\mathrm{CV}$ ) of each species for each parameter that was determined. To determine the significant differences between the species for each parameter, a nonparametric test (Kruskal-Wallis) was performed using Statgraphics Centurion XV1 (StatPoint Technologies, Warrenton, VA, USA, 2012).

\section{Results and discussion}

The main factors that affect the polyphenol content in fruits are the maturity stage at harvest, the genotype and the growing season (Josuttis et al., 2012; Wang et al., 2012a; Zhao et al., 2013). The fruits that are harvested at different maturity stages present different contents and types of polyphenols (Fredes et al., 2012; Zhao et al., 2013). Given that cultivated berry fruits are generally harvested within a relatively narrow window of maturity, this factor may have more relevance in the case of maqui berry, which is collected from wild habitats. Nevertheless, a maturity index for the maqui fruit was determined in a previous study (Fredes et al., 2012) and was used in this study. Table 1 shows the SS content of the maqui berry samples that were analyzed and indicates similar values within the selected ecotypes.

Total phenolic contents of the polyphenol-rich fruits

In this study, six species that are recognized for their high TP contents that belong to four different botanical families (Ericaceae, Rosaceae,
Punicaceae and Elaeocarpaceae) and that are called polyphenol-rich fruits were analyzed. Among these species, Rosaceae, which includes raspberries, blackberries and strawberries, has a well-documented phenolic content (Skrede et al., 2012). In contrast, within the Elaeocarpaceae family, maqui berry is the only species in Chile that has been studied for its polyphenols.

The Folin-Ciocalteu method is the most common assay that is used to estimate the TP contents in many fruits and foods. In this study, maqui berry showed the highest TP contents (14.6 $\mathrm{g} \mathrm{GAE} \mathrm{kg}^{-1}$ FW) with significant differences from the other polyphenol-rich fruits that were analyzed (Figure 1a). These results are consistent with previous studies (Miranda-Rottmann et al., 2002; Guerrero et al., 2010) in which maqui berries were compared with other polyphenol-rich fruits. However, this is the first time that maqui berry has been compared to pomegranate (Punicaceae) arils, showing an intermediate level of the TP contents (3.9 g GAE $\mathrm{kg}^{-1} \mathrm{FW}$ ). In addition, red raspberries presented the lowest TP contents $\left(3.0 \mathrm{~g} \mathrm{GAE} \mathrm{kg}^{-1} \mathrm{FW}\right)$ with significant differences from the other polyphenolrich fruits that were analyzed.

Although the Folin-Ciocalteu method overestimates the phenol content due to the presence of L-ascorbic acid (vitamin C) (Singleton and Rossi, 1965), this interference would not be present in maqui berry because vitamin $C$ has not been detected in this fruit (Miranda-Rottmann et al., 2002). A low vitamin $\mathrm{C}$ content has been described in blueberries, red raspberries and blackberries (Speisky et al., 2008). However, strawberries have been recognized for their high ascorbic acid content (Speisky et al., 2008), which can overestimate the TP contents that are measured using the Folin-Ciocalteu method.

Total anthocyanin contents of the polyphenolrich fruits

Anthocyanins are phenolic compounds that contribute to the red, blue, or purple coloration of many 
fruits and are well known for their antioxidant activity. The principal method for the quantification of anthocyanins is the $\mathrm{pH}$ differential method, which is widely used in industry, because it is a rapid and easily performed procedure (Lee et al., 2005). In this study, maqui berry showed the highest TA contents $(9.3 \mathrm{~g}$ cy-3-glu kg-1 $\mathrm{FW})$ with significant differences from the other polyphenolrich fruits that were analyzed (Figure 1b). Similar to the TP contents, the TA results are consistent with those of a previous study (Guerrero et al., 2010) in which maqui berries were compared with other polyphenol-rich fruits. Pomegranate arils showed an intermediate level of TA contents $(0.5$ g cy-3-glu kg-1 FW).
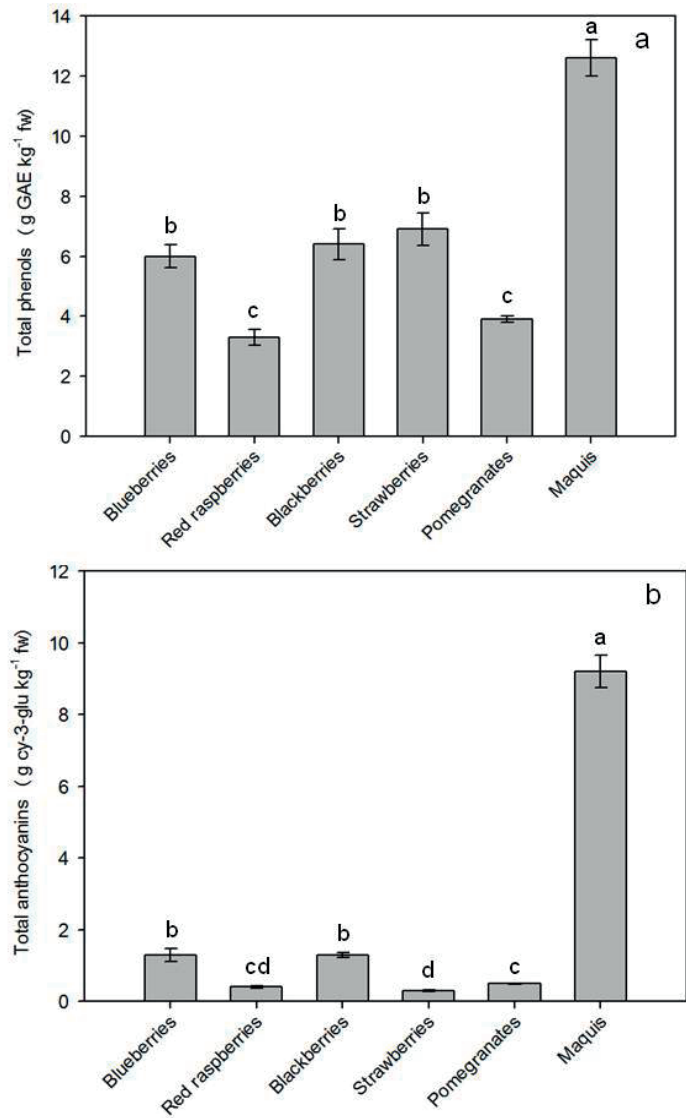

Figure 1. Total phenolic contents (a) and total anthocyanin contents (b) of the polyphenol-rich fruits that were analyzed in this study. The vertical bar represents the mean and standard error of the mean for each species. The means in each bar with a different letter are significantly different (at $\mathrm{P} \leq 0.05)$. GAE: gallic acid equivalent. cy-3-glu: cyanidin3-glucoside.
The total anthocyanin content was not directly correlated with the TP contents in all of the species. Strawberry fruits showed the second highest TP contents ( $\left.6.9 \mathrm{~g} \mathrm{GAE} \mathrm{kg}^{-1} \mathrm{FW}\right)$; however, they showed the lowest TA contents $(0.3 \mathrm{~g}$ cy-3-glu $\mathrm{kg}^{-1} \mathrm{FW}$ ). These results indicate that high the TP contents in strawberry fruits may be explained by the presence of other type of polyphenols or by the L-ascorbic acid content.

Berry fruits accumulate anthocyanins mainly in the epicarp (peel) (Wang et al., 2012b). Botanically, maqui fruit corresponds to a true berry, and its high anthocyanin content may also be attributed to its high surface/volume ratio as expressed by the lowest fruit weight (Table 1) in comparison to the other polyphenol-rich fruits that were analyzed. Accordingly, blackberry had the highest TA contents per fruit (7.8 mg cy-3-glu FW), whereas red raspberry had the lowest TA contents per fruit $(0.8$ mg cy-3-glu FW). Although red raspberry has a berry weight that is 11.5 -fold higher than that of maqui berry (Table 1), its TA contents were 2.8fold lower than those of maqui berry, whose TA contents per fruit were $1.4 \mathrm{mg}$ cy-3-glu FW.

Antioxidant activity of the polyphenol-rich fruits

Different methods exist to evaluate the AA (Mermelstein, 2008), both in vitro and in vivo. In this study, two in vitro methods were performed. The FRAP method measures the reduction of ferric ion $\left(\mathrm{Fe}^{3+}\right)$ to ferrous ion $\left(\mathrm{Fe}^{2+}\right)$ in the presence of antioxidants (Benzie and Strain, 1996), whereas the 2,2-diphenylpicrylhydrazyl (DPPH) radical scavenging capacity method measures the capacity of the antioxidant compounds to scavenge the DPPH radical (Brand-Williams et al., 1995). For the DPPH method, the results were expressed as $\mathrm{EC}_{50}$ (milligrams of sample that bleached $50 \%$ of the DPPH methanolic solution); therefore, the lowest $\mathrm{EC}_{50}$ values indicate the highest AA.

As with the TP and TA contents, maqui berry showed the highest AA when both the FRAP 
Table 1. Characteristics of the fruit samples that were analyzed in this study.

\begin{tabular}{|c|c|c|c|c|}
\hline Species/Variety & Date of harvest & Geographical origin & SS & FW \\
\hline \multicolumn{5}{|l|}{ Blueberry } \\
\hline Aurora & $12 / 01 / 17$ & Los Angeles, VIII R & 11.4 & 1.8 \\
\hline Aurora & $12 / 01 / 18$ & Molina, VII R & 12.7 & 1.5 \\
\hline Brigitta & $12 / 01 / 17$ & Los Angeles, VIII R & 12.5 & 1.8 \\
\hline Elliot & $12 / 01 / 17$ & Los Angeles, VIII R & 10.9 & 1.5 \\
\hline Legacy & $11 / 12 / 13$ & San Clemente, VII R & 14.7 & 1.7 \\
\hline Legacy & $11 / 12 / 14$ & Curepto, VII R & 14.5 & 2.1 \\
\hline Legacy & $11 / 12 / 16$ & San Clemente, VII R & 14.9 & 1.8 \\
\hline Legacy & $12 / 01 / 17$ & Los Angeles, VIII R & 15.1 & 1.7 \\
\hline Liberty & $12 / 01 / 17$ & Los Angeles, VIII R & 17.5 & 1.4 \\
\hline Ozarkblue & $12 / 01 / 17$ & Los Angeles, VIII R & 11.6 & 1.7 \\
\hline \multicolumn{5}{|l|}{ Red raspberry } \\
\hline Heritage & $12 / 01 / 20$ & Nogales, V R & 10.6 & 1.8 \\
\hline Heritage & $12 / 01 / 20$ & Nogales, V R & 12.3 & 2.9 \\
\hline Heritage & $12 / 02 / 10$ & Nogales, V R & 10.5 & 2.2 \\
\hline \multicolumn{5}{|l|}{ Blackberry } \\
\hline Navaho & $12 / 01 / 20$ & Nogales, V R & 17.4 & 3.1 \\
\hline Prime-Jim & $12 / 02 / 16$ & Nogales, V R & 11.7 & 7.2 \\
\hline Prime-Jan & $12 / 02 / 16$ & Nogales, V R & 13.0 & 7.6 \\
\hline \multicolumn{5}{|l|}{ Strawberry } \\
\hline Camarosa & $12 / 02 / 03$ & Santo Domingo, V R & 9.1 & 16.7 \\
\hline Sabrina & $12 / 02 / 03$ & Santo Domingo, V R & 7.6 & 17.6 \\
\hline Sabrosa & $12 / 02 / 03$ & Santo Domingo, V R & 7.8 & 15.2 \\
\hline Siba & $12 / 02 / 03$ & Santo Domingo, V R & 10.0 & 14.5 \\
\hline \multicolumn{5}{|l|}{ Pomegranate } \\
\hline Wonderful & $12 / 03 / 30$ & Longotoma, V R & 15.0 & n.a \\
\hline Wonderful & $12 / 03 / 30$ & Longotoma, V R & 15.3 & n.a \\
\hline \multicolumn{5}{|l|}{ Maqui berry } \\
\hline n.i & $11 / 12 / 21$ & Puchuncavi, V R & 18.0 & 0.1 \\
\hline n.i & $12 / 01 / 10$ & Paredones, VI R & 18.4 & 0.2 \\
\hline n.i & $12 / 01 / 30$ & Talca, VII R & 19.0 & 0.2 \\
\hline n.i & $12 / 02 / 15$ & Pucon, IX R & 17.8 & 0.2 \\
\hline
\end{tabular}

n.i: not identified. The maqui berries correspond to different ecotypes. n.a: not applicable for pomegranate arils. SS: soluble solid in ${ }^{\circ}$ Brix. FW: fruit weight in grams.

(152.0 $\left.\mathrm{mmol} \mathrm{Fe}^{2+} \mathrm{kg}^{-1} \mathrm{FW}\right)$ and DPPH (1.5 mg FW) methods were used and exhibited significant differences from the other polyphenol-rich fruits that were analyzed (Figure 2). These results are consistent with the research of Araya et al. (2006) in which different fruits and vegetables that are consumed in Chile were compared using the FRAP method. Nevertheless, our results were higher, suggesting that the extraction method could be responsible for this difference. Similar to the TP and TA contents, the AA of pomegranate had not been previously compared to that of maqui berry. Pomegranate arils showed an intermediate level of AA $\left(36.0 \mathrm{mmol} \mathrm{Fe} \mathrm{kg}^{2+}\right.$ and $22.0 \mathrm{mg}$ FW). However, red raspberries, with similar TP contents, presented the lowest AA by both the FRAP (38.3 mmol Fe $\left.{ }^{2+} \mathrm{kg}^{-1} \mathrm{FW}\right)$ and DPPH (33.7 mg FW) methods.

A high correlation $(\mathrm{n}=78)$ between $\mathrm{TP}-\mathrm{EC}_{50}(\mathrm{r}=$ 0.701), TP-FRAP $(r=0.926)$, TA-EC $_{50}(r=0.824)$ and TA-FRAP $(r=0.953)$ were found. Similar results in which the TP contents were more strongly correlated with the AA in polyphenolrich fruits were obtained by Lohachoompol et al. (2008), Guerrero et al. (2010) and Caliskan and Bayazit (2012). The lowest correlation between the TP content and $\mathrm{EC}_{50}$ (DPPH method) could be explained by the incubation time that was used to perform the kinetics of reaction for each 
sample. Dawidowicz et al. (2012) indicate that a short incubation time is frequently not sufficient to reach the steady state of the reaction DPPH/ sample antioxidants because some antioxidants require more time than others for the hydrogen atom to be donated, which is necessary to reduce the DPPH radical.

The AA that were determined by both the FRAP and DPPH methods for the different polyphenolrich fruits that were analyzed in this study validate the potential of these fruits as good sources of phenolic antioxidants. Nevertheless, the in vitro determination of the AA only provides an approximate idea of what happens in complex in vivo situations (Mermelstein, 2008) because the absorption of the polyphenols and therefore the real effectiveness in the organism will depend on the bioavailability of the individual phenolic compounds of each fruit.

Total phenolic contents, total anthocyanin contents and antioxidant activity in the polyphenol-rich fruit species

The health benefits that are attributed to polyphenols in the diet have stimulated research to investigate the total antioxidant activity of different fruit and vegetable genotypes. Many authors indicate that the genotype-variety is the major factor in determining the fruit nutritional quality (Capocasa et al., 2008a; Lohachoompol et al., 2008; Josuttis et al., 2012).

According to our results, the coefficients of variation for each parameter were very high, suggesting the effect of different genotypes within each species (Table 2). Significant biochemical differences between varieties have been reported for (highbush) blueberries (Lohachoompol et al., 2008; Koca and Karadeniz, 2009; Skrede et al., 2012; Wang et al., 2012a), blackberries (Koca and Karadeniz, 2009), strawberries (Capocasa et al., 2008a; Josuttis et al., 2012; Skrede et al., 2012), red raspberries (Skrede et al., 2012) and
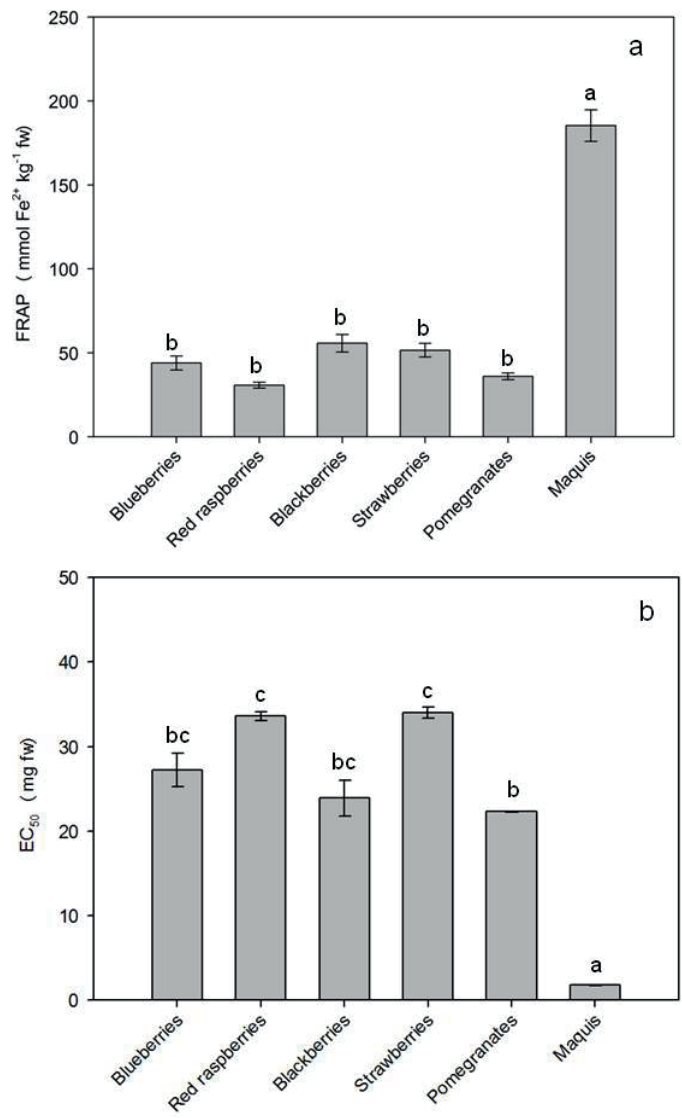

Figure 2. Antioxidant activity as measured by the FRAP (a) and DPPH (b) methods of the polyphenol-rich fruits that were analyzed in this study. The vertical bar represents the mean and standard error of the mean for each species. The means in each bar with a different letter are significantly different (at $\mathrm{P} \leq 0.05$ ). FRAP: ferric-reducing antioxidant power. $\mathrm{EC}_{50}$ : milligrams of sample that bleached $50 \%$ of the DPPH methanolic solution.

pomegranates (Caliskan and Bayazit, 2012; Zhao et al., 2013). However, for these last two species, mainly one variety (Heritage and Wonderful, respectively) is intensely cultivated in Chile and was considered in this study.

For each polyphenol-rich fruit species, the values for the different parameters that were analyzed in this study were in the range that is described in the literature (Table 3). However, references for every varieties were not found in the literature, or part of the information in the literature could not be compared with the results of this study because the results were expressed in other units (such as $\mathrm{mg} \mathrm{L}^{-1}$ ) or as a different type of com- 
Table 2. Total phenolic (TP) contents, total anthocyanin (TA) contents and antioxidant activity (FRAP, $\mathrm{EC}_{50}$ ) of the fruit samples that were analyzed in this study.

\begin{tabular}{|c|c|c|c|c|}
\hline Species/Variety & $\mathrm{TP}$ & TA & FRAP & $\mathrm{EC}_{50}$ \\
\hline \multicolumn{5}{|l|}{ Blueberry } \\
\hline Aurora $(\mathrm{n}=2)$ & $4.8-5.3$ & $0.8-1.0$ & $30-34$ & $32-33$ \\
\hline Brigitta $(\mathrm{n}=1)$ & 6.1 & 1.5 & 43 & 29 \\
\hline Elliot $(n=1)$ & 8.4 & 2.6 & 68 & 21 \\
\hline Legacy $(n=4)$ & $5.2-7.2$ & $1.0-1.7$ & $37-59$ & $23-31$ \\
\hline Liberty $(\mathrm{n}=1)$ & 6.7 & 1.5 & 52 & 15 \\
\hline Ozarkblue (n=1) & 4.9 & 0.9 & 31 & 33 \\
\hline $\mathrm{CV}$ & 42 & 20 & 30 & 23 \\
\hline \multicolumn{5}{|l|}{ Red raspberry } \\
\hline Heritage $(n=3)$ & $2.1-3.8$ & $0.2-0.5$ & $21-34$ & $33-34$ \\
\hline $\mathrm{CV}$ & 19 & 14 & 10 & 3 \\
\hline \multicolumn{5}{|l|}{ Blackberry } \\
\hline Navaho $(\mathrm{n}=1)$ & 7.4 & 1.5 & 65 & 21 \\
\hline Prime-Jim (n=1) & 5.9 & 1.2 & 47 & 28 \\
\hline Prime-Jan $(\mathrm{n}=1)$ & 5.8 & 1.3 & 55 & 23 \\
\hline $\mathrm{CV}$ & 10 & 14 & 16 & 16 \\
\hline \multicolumn{5}{|l|}{ Strawberry } \\
\hline Camarosa $(\mathrm{n}=1)$ & 6.3 & 0.3 & 44 & 33 \\
\hline Sabrina $(\mathrm{n}=1)$ & 6.5 & 0.3 & 49 & 36 \\
\hline Sabrosa $(n=1)$ & 8.5 & 0.3 & 63 & 33 \\
\hline Siba $(n=1)$ & 6.3 & 0.4 & 50 & 34 \\
\hline $\mathrm{CV}$ & 17 & 16 & 16 & 4 \\
\hline \multicolumn{5}{|l|}{ Pomegranate } \\
\hline Wonderful $(\mathrm{n}=2)$ & $3.8-4.0$ & 0.5 & $34-38$ & 22 \\
\hline $\mathrm{CV}$ & 3 & 4 & 8 & 0 \\
\hline \multicolumn{5}{|l|}{ Maqui berry } \\
\hline n.i $(\mathrm{n}=1)$ & 12.3 & 6.2 & 140 & 1.6 \\
\hline n. $\mathrm{i}(\mathrm{n}=1)$ & 15.8 & 12.0 & 168 & 1.3 \\
\hline n.i $(n=1)$ & 15.0 & 10.8 & 170 & 1.3 \\
\hline $\mathrm{n} . \mathrm{i}(\mathrm{n}=1)$ & 13.7 & 8.0 & 130 & 1.7 \\
\hline $\mathrm{CV}$ & 10 & 10 & 10 & 0.7 \\
\hline
\end{tabular}

pound equivalent (catechins) or other extraction methods were used.

Among the blueberry varieties, Elliot stands out for its high TP contents ( $\left.8.4 \mathrm{~g} \mathrm{GAE} \mathrm{kg}^{-1} \mathrm{FW}\right)$, TA contents (2.6 g cy-3-glu kg-1 FW) and AA (68.1 $\mathrm{mmol} \mathrm{Fe} \mathrm{kg}^{2+} \mathrm{kg}^{-1}$ and $21.1 \mathrm{mg} \mathrm{FW}$ ), and our results are consistent with those studies that were performed using this variety (Table 3). Elliot is also a late-ripening variety whose fruits ripen later in the harvest season and, therefore, contain more soluble phenolics and exhibit higher AA than those of other polyphenol-rich fruits (Caliskan and Bayazit, 2012).
Among the blackberry varieties, Navaho stands out for its TP contents (7.4 g GAE kg $\left.{ }^{-1} \mathrm{FW}\right)$, TA contents $\left(1.5 \mathrm{~g}^{\mathrm{c}} \mathrm{-}-3\right.$-glu kg-1 $\left.\mathrm{FW}\right)$ and AA (65.3 mmol Fe ${ }^{2+} \mathrm{kg}^{-1}$ and $\left.20.7 \mathrm{mg} \mathrm{FW}\right)$. Similar TP contents, TA contents and AA between Prime-Jim and Prime-Jan are expected due to the genetic similarities of these varieties (they both result from a cross with the parent "Arapaho") (Clark et al., 2005) and their cultivation in the same geographical area.

In the last 10 years, strawberry selection and breeding programs have been incorporated in the quantification of bioactive compounds as an 
Table 3. Range of the total phenolic (TP) contents, total anthocyanin (TA) contents and antioxidant activity (FRAP) that is described in the literature for the polyphenol-rich fruit species/varieties that were analyzed in this study.

\begin{tabular}{|c|c|c|c|c|}
\hline Species/Variety & $\mathrm{TP}$ & TA & FRAP & Reference \\
\hline \multicolumn{5}{|l|}{ Blueberry } \\
\hline-- & $2.8-3.9$ & $0.9-1.7$ & $28-53$ & Skrede et al. (2012) \\
\hline-- & $2.6-3.2$ & $2.2-2.8$ & & Wang et al. (2012a) \\
\hline-- & $0.8-8.2$ & & & Koca and Karadeniz (2009) \\
\hline Elliot & $3.9-4.5$ & $3.5-4.1$ & & Wang et al. (2012a) \\
\hline \multicolumn{5}{|l|}{ Red raspberry } \\
\hline-- & $1.5-3.5$ & $0.3-0.7$ & $24-47$ & Skrede et al. (2012) \\
\hline \multicolumn{5}{|l|}{ Blackberry } \\
\hline Navaho & 2.1 & 1.0 & 36 & Koca and Karadeniz (2009) \\
\hline Arapaho* & 2.2 & 1.2 & 38 & Koca and Karadeniz (2009) \\
\hline \multicolumn{5}{|l|}{ Strawberry } \\
\hline-- & $1.4-2.6$ & $0.1-0.4$ & $19-31$ & Skrede et al. (2012) \\
\hline-- & $1.5-3.2$ & $0.3-0.9$ & & Josuttis et al. (2012) \\
\hline Camarosa & 2.6 & & & Capocasa et al. (2008a) \\
\hline \multicolumn{5}{|l|}{ Pomegranate } \\
\hline-- & $1.1-9.5$ & $0.01-0.6$ & & Caliskan and Bayazit (2012) \\
\hline \multicolumn{5}{|l|}{ Maqui berry } \\
\hline n.i & & & 120 & Araya et al. (2006) \\
\hline
\end{tabular}

evaluation criterion (Capocasa et al., 2008b). This incorporation is particularly important in strawberries because a large number of new varieties have been registered in the United States and Europe and because the top variety in the world is the Camarosa, which covers approximately $50 \%$ of the world market. According to our results, the Sabrosa variety stands out for its high TP contents $\left(8.5 \mathrm{~g} \mathrm{GAE} \mathrm{kg}^{-1} \mathrm{FW}\right)$ and $\mathrm{AA}(63.0 \mathrm{mmol}$ $\mathrm{Fe}^{2+} \mathrm{kg}^{-1}$ and $\left.33.0 \mathrm{mg} \mathrm{FW}\right)$. Nevertheless, similar TA contents $\left(0.3-0.4 \mathrm{~g}\right.$ cy-3-glu $\left.\mathrm{kg}^{-1} \mathrm{FW}\right)$ were observed in the four varieties that were analyzed.

Differences in the TP contents, TA contents and AA were observed in the maqui berry ecotypes from different geographical areas, which could also be explained by the different genotypes of the analyzed fruit samples. Maqui berry is a dioecious plant with cross pollination (Fredes et al., 2012); therefore, a high variability of genotypes may be observed in wild populations.

As mentioned above, the polyphenol content is also affected by different growth environments. In this study, it is difficult to determine the ef- fect of the environment on the obtained results because not all of the varieties were grown in the same geographical area (Table 1).

This study compared the polyphenolic status of the main polyphenol-rich fruit species that are grown in Chile. There was a wide variation in the TP contents, TA contents and AA among the six polyphenol-rich fruits, and maqui berry showed the highest TP contents, TA contents and AA compared to those of the other red fruits that are recognized for their high polyphenol contents. Our study also showed that these values can also vary between different varieties/ecotypes. Nevertheless, the in vitro-generated AA values of the fruits cannot be extrapolated to in vivo effects, and bioavailability studies to test the benefits of dietary antioxidants should be performed in order to establish clear scientific evidence in this area.

\section{Acknowledgements}

A CONICYT grant was provided to pursue doctoral studies in Chile. A FONDECYT grant 
(1110808) was also provided to support this work. Strawberries, blackberries and raspberries were kindly provided by Professors Marina Gambardella and Pilar Bañados from the Departamento de Fruticultura, Facultad de Agronomía, Pontificia Universidad Católica de Chile.

\section{Resumen}

C. Fredes, G. Montenegro, J.P. Zoffoli, F. Santander y P. Robert. 2014. Comparación de los contenidos de fenoles totales, antocianos totales $\mathrm{y}$ la actividad antioxidante de frutos ricos en polifenoles que crecen en Chile. Cien. Inv. Agr. 41(1): 49-60. Durante los últimos 10 años, el interés en la investigación de los frutos ricos en polifenoles ha incrementado debido a sus potenciales efectos beneficiosos para la salud atribuidos principalmente a contenidos altos de antocianinas y una alta actividad antioxidante. Seis especies de frutos ricos en polifenoles (arándanos, frambuesas, moras, frutillas, granadas y maquis) fueron cosechados en el mismo estado de madurez durante la misma temporada de producción y comparadas de acuerdo a sus contenidos de fenoles totales (método Folin Ciocalteu), antocianinas totales (método pH diferencial) y actividad antioxidante determinada por los métodos de FRAP (poder antioxidante para reducir el hierro férrico) y del radical DPPH (2,2-diphenylpicrylhydrazil). Los resultados de este estudio permiten comparar el estatus polifenólico de los principales frutos ricos en polifenoles que crecen en Chile, donde el maqui presenta el mayor contenido de fenoles totales (14,6 $\mathrm{g} \mathrm{EAG} \mathrm{kg}^{-1} \mathrm{pf}$ ), antocianinas totales (9,3 $\mathrm{g}$ ci-3-glu kg-1 pf), y actividad antioxidante (152,0 mmol Fe $\mathrm{mg}^{+1}$ and 1,5 mg pf) con diferencias significativas con las otras especies de frutos analizadas. Sin embargo, se deben realizar estudios de biodisponibilidad para probar los efectos benéficos sobre la salud humana de los antioxidantes de esta especie para poder establecer evidencia científica en esta área.

Palabras clave: Berries, DPPH, FRAP, granada, maqui.

\section{References}

Araya, H., C. Clavijo, and C. Herrera. 2006. Capacidad antioxidante de frutas y verduras cultivadas en Chile. Archivos Latinoamericanos de Nutrición 56:361-365.

Benzie, I.F.F., and J.J. Strain. 1996. The ferric reducing ability of plasma (FRAP) as a measure of "antioxidant power": the FRAP assay. Analytical Biochemistry 239:70-76.

Brand-Williams, W., M.E. Cuvelier, and C. Berset. 1995. Use of a free radical method to evaluate antioxidant activity. Lebensmittel-Wissenschaft \& Technologie 28:25-30.

Caliskan, O., and S. Bayazit. 2012 Phytochemical and antioxidant attributes of autochthonous Turkish pomegranates. Scientia Horticulturae 147:81-88.
Capocasa, F., J. Scalzo, B. Mezzetti, and M. Battino. 2008a. Combining quality and antioxidant attributes in the strawberry: The role of genotype. Food Chemistry 111:872-878.

Capocasa, F., J. Diamanti, S. Tulipani, M. Battino, and B. Mezzetti. 2008b. Breeding strawberry (Fragaria $\mathrm{x}$ ananassa Duch) to increase fruit nutritional quality. Biofactors 34:67-72.

Clark, J.R., J.N. Moore, J. Lopez-Medina, C. Finn, and P. Perkins-Veazie. 2005. "Prime-Jim" ("APF-8") and Prime-Jan ("APF-12") primo cane-fruiting blackberries. Hortscience 40:852855.

Dawidowicz, A.L., D. Wianowska, and M. Olszowy. 2012. On practical problems in estimation of antioxidant activity compounds by DPPH method (problems in estimation of antioxidant activity). Food Chemistry 131:1037-1043. 
De Pascual-Teresa, S., and M.T. Sanchez-Ballesta. 2008. Anthocyanins: from plant to health. Phytochemistry Reviews 7:281-299.

Fredes, C., G. Montenegro, J.P. Zoffoli, M. Gómez, and P. Robert. 2012. Polyphenol content and antioxidant activity of maqui (Aristotelia chilensis [Mol.] Stuntz) during fruit development and maturation in Central Chile. Chilean Journal of Agricultural Research 72:582-589.

Guerrero C., J., L. Ciampi P., A. Castilla C., F. Medel S., H. Schalchli S., E. Hormazabal U., E. Bensch T., and M. Alberdi L. 2010. Antioxidant capacity, anthocyanins, and total phenols of wild and cultivated berries in Chile. Chilean Journal of Agricultural Research 70:537-544.

Jimenez, P., L. Masson, A. Barriga, J. Chávez and P. Robert. 2011. Oxidative stability of oils containing olive leaf extracts obtained by pressure, supercritical and solvent-extraction. European Journal of Lipid Science and Technology 113:497-505.

Josuttis, M., C. Carlen, P. Crespo, R. Nestby, T.B. Toldam-Andersen, H. Dietrich, and E. Krüger. 2012. A comparison of bioactive compounds of strawberry fruit from Europe affected by genotype and latitude. Journal of Berry Research 2:73-95.

Koca, I. and B. Karadeniz. 2009. Antioxidant properties of blackberry and blueberry fruits grown in the Black Sea Region of Turkey. Scientia Horticulturae 121:447-450.

Lee, J., R.W. Durst, and R.E. Wrolstad. 2005. Determination of total monomeric anthocyanin pigment content of fruit juices, beverages, natural colorants, and wines by the $\mathrm{pH}$ differential method: Collaborative study. Journal of AOAC International 88:1269-1278.

Lohachoompol, V., M. Mulholland, G. Srzednicki, and J. Craske. 2008. Determination of anthocyanins in various cultivars of highbush and rabbiteye blueberries. Food Chemistry 111:249-254.

Mermelstein, N.H. 2008. Determining antioxidant activity. Food Technology 11:63-66.

Miranda-Rottmann, S., A. Aspillaga, R. Pérez, L. Vásquez, F. Martínez, and F. Leighton. 2002. Juice and phenolic fractions of the berry Aristotelia chilensis inhibit LDL oxidation in vitro and protect human endothelial cells against oxidative stress. Journal of Agricultural and Food Chemistry 50:7542-7547.

ODEPA-Oficina de Estudios y Políticas Agrarias. 2012. Boletín frutícola. ODEPA, Ministerio de Agricultura. Santiago, Chile. 28 pp.

Schreckinger, M.E, J. Lotton, M.A. Lila, and E. Gonzalez de Mejia. 2010. Berries from South America: A Comprehensive Review on Chemistry, Health Potential, and Commercialization. Journal of Medicinal Food 13:233-246.

Seeram, N. 2008. Berry fruits: compositional elements, biochemical activities, and the impact of their intake on human health, performance, and disease. Journal of Agricultural and Food Chemistry 56:627-629.

Singleton, V.L., and J.A. Rossi. 1965. Colorimetry of total phenolics with phosphomolybdic-phosphotungstic acid reagents. American Journal of Enology and Viticulture 16:144-158.

Skrede, G., B.K. Martinsen, A-B. Wold, S-E. Birkeland, and K. Aaby. 2012. Variation in quality parameters between and within 14 Nordic tree fruit and berry species. Acta Agriculturae Scandinavica Section B-Soil and Plant Science 62:193-208.

Speisky, H., A. Peña, M. Gómez, C. Fredes, M. Hurtado, M. Gotteland, and O. Brunser. 2008. Antioxidants in chilean berries. Acta Horticulturae (ISHS) 777: 485-492.

Wang, S.Y., H. Chen, M.J. Camp, and M.K. Ehlenfeldt. 2012a. Genotype and growing season influence blueberry antioxidant capacity and other quality attributes. International Journal of Food Science and Technology 47:1540-1549.

Wang, S.Y., M.J. Camp, and M.K. Ehlenfeldt. 2012 b. Antioxidant capacity and alpha-glucosidase inhibitory activity in peel and flesh of blueberry (Vaccinium spp.) cultivars. Food Chemistry 132:1759-1768.

Zhao, X., Z. Yuan, Y. Fang, Y. Yin, and L. Feng. 2013. Characterization and evaluation of major anthocyanins in pomegranate (Punica granatum L.) peel of different cultivars and their development phases. European Food Research and Technology A 236:109-117. 
